\title{
EDITORIAL: ART AS BUSINESS
}

\author{
Christopher Fox
}

One of the recurring features of music festivals is the sponsors' reception, the moment when festival organisers gather people together to acknowledge the contribution made by the organisations that have put up the money that made the whole thing possible. They're usually quite unsatisfactory events, often sandwiched between concerts. The constituency that might have enjoyed a free glass of wine and a canapé the most, the audience members who paid for their tickets, aren't invited; instead these receptions are dominated by the least grateful constituency, the artists, who regard them as an alternative to going out in the cold in an unfamiliar city and trying to find something to eat and drink.

Inevitably there are speeches, often the spur for the artists to decide that, after all, it might be worth setting off in search of something more sustaining than a glass of fizz and a vol-au-vent. The speeches are full of names and gratitude, and are interspersed with assertions about the uniqueness of this particular festival, but occasionally there's a surprise. Many years ago I was at just such a reception when, in the gap between speeches, Hans Werner Henze interrupted to give a brief, gracious vote of thanks to the festival promoters on behalf not only of all the artists who had benefitted from it but also of music itself.

Less surprising, perhaps, and rather more disturbing, was a more recent occasion at which a festival director claimed that their festival was not just a 'place to listen to music, but also a place to do business'. What did this mean? That local call-centre managers, retailers and financial service providers would be mingling with audiences to sell their products? But there was very little evidence of a local corporate presence in the programme book advertising. Instead what was meant was that the festival itself was full of products - principally musical works and their makers - and that the festival was a market-place in which these products could be bought or licensed for re-sale elsewhere.

Perhaps I am missing something, but this seems like a very poor sort of business. One of the defining characteristics of the sort of new music promoted at contemporary music festivals, by specialist record labels, and indeed by TEMPO, is that none of the people involved expects to make their fortune. If I go to a concert, hear some wonderful music and decide that TEMPO should feature it, I don't think that counts as 'business'. Nor is it business if my co-editor, Heather Roche, encounters a new composer and decides to commission a clarinet piece from them; there will be a series of transactions, all of them involving time and money, between that initial encounter and the eventual premiere but they are just steps along the way to making art, not business.

I think this a point worth labouring because the language of business is insidious and corrupting. The USA has a president who sees all human activity as a series of transactions in which there are winners and losers, and this crude ideology has poisoned civil society in his 
country. In the UK we have become so used to an advocacy for the arts that emphasises how much money the creative sector generates, either directly or tangentially, that it is easy to forget that art's primary function is to enhance people's lives, to enable them to feel differently.

We can also trace the insidious corruption of business-think into subjects that TEMPO has addressed over the last few years. The debate about whether or not the creative act of composing music is also a form of research was introduced by John Croft's article, 'Composition is not research' in TEMPO 272. That this was a live issue was confirmed by the on-line readership for Croft's article, the most referenced and cited article TEMPO has ever published. But although Croft's arguments were based in his own philosophical misgivings about the designation of composition as research, the article was controversial because his conclusions threatened the economics of music in universities and colleges. Research in UK universities has become business. Researchers must generate funding, through grant income and through the government's periodic reviews of 'research excellence'. Were composition not to be considered as research there would be no more cash.

Even schemes which could at first sight appear to exist to develop the next generation of artists have been monetised. Many music organisations promote competitions that offer emerging composers the chance to submit their work for possible performances but many of them also charge a fee. One might imagine that promoters and ensembles would be willing to commit their resources to finding new talent, but business-think now encourages them to think of this activity as revenue-generating: charge 100 aspiring composers $£ 15$ each and your organisation has already begun to cover its costs.

Are these aggressive business models gendered? In the World of Trump it's difficult to deny a connection between his predatory version of masculinity and the reduction of everything we do to a cash value. In the world of music it's also difficult to deny that male hegemony is reluctant to cede its position. The editorial for TEMPO 284, 'Too much noise', exposed the way in which Gaudeamus in the Netherlands deployed its use of anonymous competition submissions to excuse its all-male list of prizewinners. More recently the OPUS2018 scheme promoted by the Britten Sinfonia has also produced an all-male shortlist. Again, when people protested, a system of anonymous submissions and an objective selection process was cited as a common-sense defence against bias. But perhaps 'anonymity' and 'objectivity' aren't enough: as Gramsci argued in the 1930s, 'common sense' is inevitably conservative. A new world, in which men and business give way to people and art, needs new thinking. 